Revista lus et Praxis, Año 21, No 2, 2015, pp. 199 - 224

ISSN 0717 - 2877

Universidad de Talca - Facultad de Ciencias Jurídicas y Sociales

Antecedentes histórico-jurídicos del arbitraje interno en Chile.

Planteamientos para una revisión estructural impostergable

Eduardo Jequier Lehuedé

Trabajo recibido el 16 de octubre de 2014 y aprobado el 7 de julio de 2015

\title{
Antecedentes histórico-jurídicos del arbitraje interno en Chile. Planteamientos para una revisión estructural impostergable*
}

HISTORICAL BACKGROUND OF THE DOMESTIC LEGAL ARBITRATION

in Chile. Approaches for urgent Structural ReVIEW

Eduardo JeQuier LeHUedÉ*-**

\section{RESUMEN}

El presente trabajo apunta a revisar la evolución histórica del arbitraje, con especial referencia al derecho español en cuanto fuente de la legislación actualmente vigente en Chile sobre arbitraje interno. El estudio histórico-jurídico del arbitraje permitirá identificar y comprender, precisamente, el origen de las dificultades que ha experimentado dicha institución en su desarrollo y la errática evolución dogmática que ha tenido en el tiempo, con concepciones doctrinales y manifestaciones normativas marcadas por el contexto histórico-político en que cada una de ellas se inserta, respectivamente. Dicho análisis adquiere una relevancia especial si se considera que el fenómeno apuntado se proyecta hasta nuestros días a través de figuras que, como el arbitraje forzoso o la revisión del mérito del laudo por la justicia ordinaria, se mantienen enquistadas aun en nuestro ordenamiento jurídico sobre arbitraje interno, pese a tener un origen bien definido en el derecho medieval castellano y, por ende, en un contexto de poder monárquico absolutista que nada tiene que ver con el constitucionalismo moderno que impera en la actualidad. La investigación, por lo mismo, muestra así una clara vocación de lege ferenda.

\section{ABSTRACT}

This paper reviews the historical development of arbitration, with special reference to the laws of Spain: the main source of legislation on domestic arbitration currently in force in Chile. The historical study of arbitration law allows to identify and understand the origin of the difficulties experienced by arbitration in its development and the erratic dogmatic evolution trough history. Dogmatic evolution has been full of doctrinal concepts and standards that need to be put into historical and political context.

This analysis is especially relevant when considering that those difficulties have arrived to our time as legal institutions such us compulsory arbitration or merit review by the ordinary court, despite medieval Castilian origin and, therefore, an absolute monarchy origin that has

\footnotetext{
* Trabajo realizado en el marco del Proyecto Anillo de Investigación en Ciencias Sociales CONICYT SOC1406.

** Doctor en Derecho, Universitat de Valencia. Mg. en Derecho de la Empresa, P. Universidad Católica de Chile. Profesor de Derecho Comercial, Universidad de Los Andes, Chile (Av. Monseñor Álvaro del Portillo 12.455, Las Condes, Santiago). E.mail: ejequier@uandes.cl.
} 
nothing to do with modern constitutionalism. Therefore, this paper has a clear vocation de legel ferenda.

\section{PALABRAS CLAVE}

Historia del arbitraje, Arbitraje interno, Chile, Arbitraje forzoso,

Derecho castellano, Derecho romano

KEY WORDS

History of arbitration, Domestic arbitration, Chile, Compulsory arbitration,

Castilian Law, Roman Law

\section{Introducción}

Remontarnos en el tiempo, en busca del específico origen del arbitraje como mecanismo de solución heterocompositiva de conflictos, anterior incluso al proceso y al concepto de jurisdicción como hoy se conoce, presenta obstáculos y desafíos difíciles de abordar si consideramos que, a fin de cuentas, se trata de una institución cuya evolución ha ido a la par con la historia misma de la civilización. Me parece, además, que desentrañar el momento, el lugar y el ámbito preciso de nacimiento del arbitraje puede plantear de inicio un problema cuya solución escapa al objeto de esta investigación, con el riesgo adicional que implica el adentrarse en un camino de tal entidad con escasas fuentes monográficas y estudios específicos.

Sin embargo, nos parece al mismo tiempo que incursionar brevemente en el recorrido histórico del arbitraje, partiendo desde un origen definido o claramente reconocible como es el que se encuentra en el Derecho Romano ${ }^{1}$, constituye un ejercicio necesario y útil. Como dice De Castro ${ }^{2}$, el arbitraje no nos viene dado a priori pues, por el contrario, constituye una figura cambiante en el tiempo como resultado del entramado social y el variado juego de intereses imperantes en cada momento y sociedad. Por lo mismo, volver la mirada al pasado nos permitirá conocer los principales aspectos de la institución y su eficacia como sistema de solución de conflictos, por una parte; y nos llevará también a constatar, por otro lado, las dificultades que ha experimentado en su desarrollo histórico y la errática evolución dogmática que ha tenido en el tiempo, con concepciones doctrinales y manifestaciones normativas marcadas precisamente por el contexto histórico-político en que cada una de ellas se generó y desenvolvió. Tal fenómeno, por lo demás, se proyecta hasta nuestros días a través de figuras que, como el arbitraje forzoso, se mantienen enquistadas aún

1 Diversas son las obras de carácter general que, con mayor o menor profundidad, abordan el desarrollo histórico del arbitraje y sus manifestaciones más remotas. Destacable resulta entre ellas la obra de Merchán Álvarez (1981).

2 De Castro (1979), p. 624. 
en nuestro ordenamiento jurídico sobre arbitraje interno, pese a tener un origen bien definido en el derecho medieval castellano y, por ende, en un contexto de poder monárquico absolutista que nada tiene que ver con el constitucionalismo moderno que impera en la actualidad.

Esta misma diversidad de concepciones, entonces, que se evidencia ya en las fuentes más remotas del Derecho Romano, hace necesaria la revisión de las mismas para definir claramente el contenido y la esencia de la institución arbitral, entendida como aquel sistema por el cual las partes acuerdan someter un conflicto de relevancia jurídica a la consideración de una o más personas independientes, designadas por ellas, por un tercero o por la justicia en subsidio, sujetándose a su decisión; y para diferenciarla por ende de otras instituciones que, calificadas también como arbitraje en las fuentes referidas, no responden, sin embargo, a la concepción heterecompositiva recién apuntada.

\section{La autonomía de la voluntad como fuente del arbitraje privado en el derecho romano}

El origen remoto del arbitraje puede encontrarse en las primeras controversias que en la antigüedad fueron sometidas a la resolución de un tercero imparcial, ya fuera el jefe de la familia, el sabio, el jefe o sacerdote de la tribu o del clan, etc. Es así como ya en la Biblia encontramos casos de arbitraje ${ }^{3}$, cuando se relata el conflicto entre Jacob y el arameo Labán, a consecuencia de los ídolos sustraídos por Raquel, esposa del primero. Más atrás incluso, y como señala Moreira Texeira ${ }^{4}$, si consideramos a las primeras tribus habitando cavernas como la forma más incipiente de vida social, ya allí podremos encontrar por cierto al arbitraje como práctica de mantención o preservación de la integridad de sus miembros.

Sin embargo, el arbitraje encuentra su origen más inmediato en el Derecho Romano clásico y justinianeo, en donde existe y convive con el ordo iudiciorum privatorum $^{5}$ hasta perder su protagonismo frente al desarrollo y fortalecimiento del Estado en la solución de los conflictos. En esta parte la doctrina romanista ha sostenido incluso, aunque no de forma unánime, que el juicio del árbitro no

\footnotetext{
${ }^{3}$ Así por ejemplo en el Génesis, 31:36-37.

${ }^{4}$ Moreira y Andreatta (1997), p. 3.

${ }^{5}$ Según el catedrático romanista Valiño, las razones de esta convivencia entre arbitraje y el procedimiento ordinario, que surge en la medida que el Estado asume el monopolio de la potestas, se encuentran fundamentalmente en que el árbitro no estaba obligado a sujetarse a la plantilla formularia, "de manera que, por ejemplo, en las reclamaciones de derecho estricto podía llevar a cabo compensaciones entre las pretensiones de las partes y en general asumir la misma actitud que desempeñaba el juez iudicia bonae fidei; y, por otra parte, porque aquellos conflictos en que el Pretor no daba una acción decretal, por no estar previstas en el Edicto, podían ser resueltas por el criterio equitativo del árbitro. VALIÑO DEL Río, en Buigues (1990), p. 19.
} 
oficial fue el origen del proceso y, por ende, la primera forma de hacer justicia en Roma. Así, y en palabras de Wlassak ${ }^{6}$, "el proceso privado romanista derivaría de una oficialización o legalización de antiguos procedimientos arbitrales y, por tanto, en el arbitraje debería verse en último término la raíz del proceso romano".

Durante la época arcaica romana, caracterizada por el sistema de las legis actiones o acciones de la ley (cinco en total), vigentes desde la Ley de las XII Tablas (462 a.C.) ${ }^{8}$ hasta el siglo II d.C., destaca -en lo que aquí concierne- la denominada legis actio per iudicis arbitrive postulationem, que habilitaba principalmente para hacer efectiva una sposio ${ }^{9}$, provocar la partición de la cosa común (actio communio dividendo) o para pedir la división del haber hereditario (actio familiae erciscundae $)^{10}$. Al tratarse de una legis actio, durante la fase in iure el magistrado que daba la acción procedía a nombrar directamente a un iudex o, en su caso, designaba al arbiter elegido por las partes para resolver la disputa, confiriéndole mandato para ello. Gaspar ${ }^{11}$, invocando un texto de las Instituciones de Gayo, señala que la fase de designación del juez o del árbitro se desarrollaba en los siguientes términos:

"El demandante manifestaba: ex sponsione te mihi $X$ milia sestertion dare oportere aio: id postulo aias an neges -afirmo que me debes dar mil sestercios en virtud de una promesa solemne: te insto a que digas si es o no cierto-. El adversario replicaba que no era verdad, y el actor decía a su vez: quando tu negas, te praetor iudicem sirve arbitrum postulo dades-puesto que lo niegas, a ti Pretor ruego que nombres un juez o un árbitro".

No existe, sin embargo, claridad en la doctrina al momento de precisar las razones que determinaban la designación de un iudex o de un arbiter. Según

\footnotetext{
${ }^{6}$ WLASSAK (1921), p. 20.

7 Su denominación como "acciones de ley" deriva de la exigencia de plantear los hechos invocados en la acción con estricto apego a los términos literales y taxativos que establecía para tal efecto la ley, bajo sanción de perder en caso contrario la acción y con ella el juicio. Se aplicaron únicamente a los ciudadanos romanos - cives romani-, como parte del ius civile romanorum.

${ }^{8}$ Para algunos autores, sin embargo, la legis actio sacramento y la manus iniectio serían anteriores a las XII Tablas. Así por ejemplo Daza y RodríGuez (1997), p. 100.

9 Promesa sacral cuyo incumplimiento no tenía en un principio más sanción que la religiosa, pero que al incorporarse a las legis actiones adquirió contenido patrimonial y pudo reclamarse judicialmente (Cervantes (2006), p. 298).

10 Según FernÁNDEZ, sin embargo, la legis actio per iudicius arbitrive postulationem (sic) sólo habilitaba para provocar la división de la herencia a través de un árbitro. La división de la cosa común, en cambio, la sitúa en la Ley Licinia del 210 a.C. (FeRNÁNDEZ, pp. 139 y 140 . Briseño, en cambio, junto con la división de la herencia y de la cosa común incluye entre estas actio la denominada "finium regundorum" y la "actio aquae pluvial arcendae". BRISEÑO (1963), p. 40.

11 Gaspar (1998), p. 29, nota 11. En el mismo sentido García (2000), pp. 196 y 197.
} 
Daza y Rodríguez ${ }^{12}$, fundados en un texto de Cicerón, la diferencia podría estar en que la designación del arbiter correspondía en aquellos casos en que la existencia de la obligación era incierta; mientras que si se trataba de una deuda cierta y determinada (pecunia certa), el nombramiento recaía en un iudex ${ }^{13}$. Para Reglero ${ }^{14}$, en cambio, el criterio diferenciador residía en la naturaleza de la cuestión litigiosa, reconociendo en todo caso la falta de uniformidad doctrinal en este punto. Así, por regla general se habrían sometido al iudex cuestiones del ius civiles stricti iuris, "mientras que el arbiter podía conocer de otras cuestiones que, aun perteneciendo también al ius civile, necesitaban para ser resueltas que se dejara al que hubiera de decidirlas una cierta libertad de apreciación, o bien en procesos que requerían gran discreción, singularmente los bonae fidei iudicia".

Junto a las acciones de la ley, la doctrina reconoce también el procedimiento formulario o per formulam, así denominado por tratarse de un escrito (fórmula) redactado por las partes y por el magistrado, quien luego lo entregaba al juez privado como guía en la resolución del conflicto. A partir del siglo II a.C., en efecto, el arbitraje convivió con el proceso formulario u oficial, manteniéndose así como una manifestación exclusiva de la voluntad de los interesados. Durante la época clásica, además, coexistieron en Roma dos tipos de árbitros, los que perduraron en el tiempo mientras que el proceso formulario terminó por desaparecer definitivamente, en el siglo IV d.C.: el arbiterex compromisso y el arbiter boni virit5.

El segundo sistema procesal que se aplicó en Roma, ya en la época postclásica, fue el de la denominada cognitio extra-ordinem ${ }^{16}$, que reemplazó al

12 Daza y Rodríguez, p. 112.

13 En el mismo sentido se pronuncian Aranglo (1980), p. 89 y D'Ors (1991), p. 171.

14 Reglero, pp. 32 y 33.

15 Buigues, tomando como base un texto del jurista Próculo -recogido siglos después en el Digesto, 17.2.76- le asigna al arbiter ex compomisso un carácter procesal, de naturaleza heterocompositiva y cuyo nombramiento derivaba del compromissum. Se trata, en consecuencia, de un arbitraje por el cual las partes optan voluntariamente para resolver una controversia jurídica, como alternativa al proceso ordinario. La opinión del árbitro (sententia), en estos casos, debía ser congruente con los límites prefijados en el compromissum, siendo además inapelable. El arbiter bonus vir, en cambio (o arbitrio de un hombre recto), tenía un carácter esencialmente negocial y su función, a diferencia del arbitrer ex compromisso, no iba más allá de emitir su opinión o estimación sobre un tema asignado. No se trataba, por ende, de un árbitro Ilamado a resolver un conflicto jurídico entre las partes, sino de uno Ilamado a completar, de manera independiente y con base en criterios objetivos, alguno de los elementos de una relación jurídica existente entre las partes (por ejemplo la determinación del precio de un contrato de compraventa, como ocurre hasta hoy) (BUIGUES (1990) pp. 31 y 57 y ss.).

16 En términos generales, la cognitio consistía en que todo el proceso, desde su inicio hasta la dictación de la sentencia, estaba a cargo de un funcionario del Estado, experto en derecho. A diferencia del ordo iudiciorum privatorum, además, en este sistema el magistrado está dotado de imperium para conocer del litigio y dictar su sentencia, haciéndola cumplir incluso por medios coercitivos. Esa sentencia, además, al emanar de un órgano público, puede ser revisada por otro magistrado de jerarquía superior. 
sistema formulario a partir de la Constitución de Constancio y Constante del año 342 d.C. En consecuencia, con la implantación de la cognitio extra-ordinem desaparece definitivamente en Roma el sistema de bipartición del proceso, con lo que el proceso pierde definitivamente su carácter privado y, por lo mismo, su naturaleza esencialmente arbitral. La implantación de este sistema, en síntesis, marca el punto de separación, hasta hoy, entre el arbitraje fundado en el compromissum y el proceso oficial, como medios de heterocomposición de disputas.

En los siglos posteriores, el arbitraje se mantuvo y convivió como alternativa al proceso ordinario. Sin embargo, paulatinamente fue perdiendo terreno como consecuencia, principalmente, de la no exigibilidad de las sentencias que imponían condenas pecuniarias, y de la falta de certeza jurídica y eficacia en el cumplimiento de las sentencias.

De lo que va dicho puede concluirse, en síntesis, que durante la evolución del Derecho Romano el arbitraje privado ${ }^{17}$, como medio de solución de conflictos jurídicos, coexistió con el procedimiento oficial de las legis actiones y con el procedimiento formulario, ambos de carácter esencialmente arbitral a mi parecer, aunque con las importantes diferencias ya apuntadas respecto del arbitraje compromisario. La misma coexistencia se observa también tras el advenimiento del proceso cognitivo extraordinario del Derecho post clásico, en que la potestad jurisdiccional es asumida íntegramente por el poder político del imperio, iniciándose con ello un paulatino proceso de desuso del arbitraje como alternativa frente al proceso oficial.

Desde su mismo origen entonces, tal como se ha ido mostrando durante las distintas etapas de su evolución, la fuente única y esencial del arbitraje en Roma -y desde mucho antes en verdad-radica en la voluntad de las partes. Es precisamente el reconocimiento de esa voluntad lo que marca el punto de partida del arbitraje en el Derecho Romano, sancionada a través del compromissum (reconocido y protegido como cualquier otro pacto lícito en un principio -nudum pactum- y reforzado luego en su cumplimiento a través de la stipulatio poenae y de la actio ex stipulatu) y del receptum (consagrado por el pretor a partir del siglo II d.C. mediante el edictum de receptis).

17 He utilizado hasta aquí este concepto para diferenciarlo del arbitraje público a que se refiere la doctrina romanista por todos, de RUGGIERO (1971), p. 34, caracterizado por la concurrencia de dos requisitos: (a) cuando las partes o el objeto del arbitraje, o ambas, eran públicas (por ejemplo conflictos entre ciudades o la fijación de límites entre provincias o estados); y (b) cuando la persona que desempeñaba el cargo tenía respaldo oficial en razón del cargo que desempeñaba o de la delegación que recibía de su titular (por ejemplo arbitrajes desempeñados por magistrados romanos o provinciales, o por senadores o el Senado mismo como órgano). Para Buigues, en cambio, sólo el segundo de los requisitos apuntados era determinante para calificar como público un arbitraje, por oposición al privado (BUIGUES (1990), p. 69). 
Como señalan Merino y Chillón" ${ }^{18}$, en fin, "el reconocimiento a las partes para que privadamente, fuera del procedimiento judicial ordinario, puedan resolver sus disputas encargando el fallo a un tercero, señala el punto de formación jurídico-técnico del arbitraje en el derecho romano".

\section{El Arbitraje en el Derecho histórico español}

En el capítulo anterior se ha pasado revista a la evolución del arbitraje privado desde los tiempos más remotos del Derecho Romano, que arroja como constante-según se dijo- el carácter esencialmente voluntario de la institución.

Retomamos ahora el mismo análisis a partir de las primeras y más relevantes fuentes normativas del arbitraje en el Derecho histórico español, que marcaron su influjo en la normativa aplicada en Chile hasta entrado el siglo XIX y, desde allí, en la legislación actualmente vigente sobre arbitraje interno. Este recorrido, que por cierto centraremos en los hitos más relevantes, permitirá definir el momento y los motivos por los cuales el arbitraje, de fuente estrictamente voluntaria según se lo conoció en sus orígenes, fue evidenciando los primeros síntomas de obligatoriedad y de intervención del poder del Estado -el monarca- en el mérito de las decisiones de los árbitros.

\section{Liber Iudiciorum, Fuero Juzgo y Fuero Real}

La segunda etapa del derecho visigodo en España, regida por el Breviario de Alarico, se caracteriza por la aparición del Liber ludiciorum (654 d.C.), que subsistió incluso después de la invasión de la península por los musulmanes, en el año 711 d.C.

En materia arbitral, el Liber marca el punto de inicio de lo que en doctrina se ha denominado como la concepción judicialista del arbitraje ${ }^{19}$, por oposición al carácter jurídico-privado del mismo; pero judicialista no en cuanto a dejar de considerarlo como mecanismo alternativo de la justicia oficial, con fuente única en la voluntad y en la libertad de las partes, sino por la potestad de juzgar que se le reconoce aquí a los árbitros, propia e inherente como sabemos a la función estatal Si bien no existe en este cuerpo de leyes un tratamiento específico del arbitraje, su Libro III, Título I (De iudicis et iudicalis), consideraba a los árbitros como jueces (iudex ex consenso partium), por lo que recibían los mismos derechos, tenían las mismas obligaciones y se los nombraba incluso de igual forma que a estos últimos ${ }^{20}$. De aquí entonces que, a partir del Liber,

\footnotetext{
18 Merino y Chillón, pp. 111 y 112.

19 Confróntese, Barona (2005); Merchán, p. 39.

${ }^{20}$ Esta circunstancia lleva a Martínez García a sostener que la función de los árbitros, en el sistema esencialmente legalista que consagró el Liber, tuvo un carácter público, considerada por lo mismo como parte del sistema estatal. (MARTínez (2000), p. 66).
} 
pierde también vigencia y se prescinde derechamente de la necesidad de estipular una pena para el cumplimiento del laudo arbitral.

Lo anterior se mantuvo luego en el Fuero Juzgo, en cuanto simple traducción del primero al romance castellano y con vigencia en Castilla hasta la época moderna ${ }^{21}$; y luego en el Fuero Real, dictado durante el reinado de Alfonso X el Sabio (1255). En este último, el arbitraje es tratado sistemáticamente en el Libro I, Título VII, "Del oficio de los alcaldes"22, y en el Libro II (sobre procedimientos en general), reconociéndose explícitamente allí la facultad de las partes para designar de común acuerdo a un tercero imparcial -alcaldes de avenienciapara dirimir un conflicto.

Destacable resulta el hecho que el Fuero Real, a diferencia de los cuerpos legales antes mencionados, procuró delimitar el ámbito material de aplicación del arbitraje al distinguir entre "pleitos de justizia" y "pleitos de otras cosas", proscribiendo la intervención de los alcaldes de avenencia en los primeros ${ }^{23}$. Se trataría, en consecuencia, de una primera manifestación legal explícita de arbitrajes prohibidos, que aún se mantiene en el Derecho chileno vigente, manteniéndose para los restantes casos la voluntad de las partes como única fuente de arbitraje.

\section{Código de las Siete Partidas}

Llegamos así al Código de las Siete Partidas, publicadas también por Alonso X el Sabio en 1256, que trata ampliamente sobre el arbitraje en la Partida III, Título IV, Leyes XXIII a XXXV, bajo la denominación genérica de jueces de avenencia.

En primer término, la Ley XXIII, "Quantas maneras son de Juezes de avenencia, e como deven ser puestos", distingue entre los árbitros o jueces de

${ }^{21}$ El Fuero Juzgo no tuvo una promulgación territorial, sino que se fue aplicando a las distintas villas y ciudades musulmanas del sur de España, como Derecho local o municipal, en la medida que eran reconquistadas por el rey castellano. Sin embargo, será aplicado en América y particularmente en Chile, hasta el siglo XIX.

22 El concepto de alcalde en el Fuero Real es utilizado para designar a funcionarios que, designados por el rey o por la voluntad de las partes, tenían la función de juzgar y aplicar las normas del mismo Fuero. "Ningun ome no sea osado de judgar pleytos, si no fuere alcalde puesto por el rey, o a placer de amas las partes, que lo tomen por avenencia, para judgar algun pleyto..." (Fuero Real, I, 7, 2). Posteriormente, las Leyes de Estilo (Leyes 213 y 218) reemplazaron este término por el de árbitro, retomándose luego en el Espéculo (Confróntese, Merchán (1981), pp. 40 y 69).

${ }^{23}$ Todos los pleitos que acaecieren también de justizia como de otras cosas, judguelo los alcalles que fueron puestos por el rey, o los que pusieren los alcaldes en su logar, asi como manda la ley; mas los alcaldes que fueron puestos por aneniencia de las partes non judgue ningun pleito de justizia". (Fuero Real, I, 7,4). No son claros, sin embargo, los datos que entrega el Fuero Real al momento de definir las materias propias de los pleitos de justicia. Sobre el particular puede consultarse a GASPAR (1998), pp. 35 y 36. 
aveniencia que eran nombrados por las partes para que juzgasen en Derecho las contiendas "como si fuesen jueces ordinarios"24_por una parte-, y los jueces de avenencia denominados en las Partidas como arbitradores, albedriadores o comunales amigos - por la otra-, nombrados también por las partes y facultados para resolver las contiendas entre éstas "en cualquier manera que ellos toviesen por bien" ${ }^{\prime 25}$, tal cual se mantiene hasta hoy en algunas legislaciones (y entre ellas la chilena ${ }^{26}$.

Se mantuvo además, tal como ocurrió en el Derecho romano, el carácter inapelable del laudo arbitral, reconociéndose, sin embargo, la posibilidad de reclamación ulterior por medio del denominado "recurso de reducción y albedrío de buen varón", cuando el laudo había sido dictado "maliciosamente o por engaño" 27 .

Especial énfasis se pone en la Partidas en cuanto al origen esencialmente voluntario del arbitraje, señalándose explícitamente allí que todo cuanto hicieren los avenidores, apartándose del mandato de las partes, carecía enteramente de valor ${ }^{28}$. Sin embargo, existe en las Partidas una primera manifestación de arbitraje forzoso en materia mercantil y, concretamente, en lo que concierne a las cuentas entre socios de una compañía ${ }^{29}$, la que junto a otros usos y

${ }^{24}$ Según Reglero, esta es la primera manifestación del arbitraje de Derecho en el Derecho medieval español (REGLERO, p. 39.)

${ }_{25}$ Partidas, III, 4, 23. Sobre el particular puede consultarse también a AlCOVER (s/f), p. 11.

${ }_{26}$ No comparto la conclusión de ReGLero (REGLERO, p. 39), en cuanto a equiparar esta figura con la del arbitrador o arbiter boni viri del Derecho romano. A diferencia de este último, en efecto, el albedriador de las Partidas es un árbitro designado por las partes no para completar una relación negocial preexistente sino, mucho más que eso, para resolver derechamente conflictos de relevancia jurídica entre ellas.

27 "Ca si maliciosamente, o por engaño fuesse dada la sentencia, devese enderecar, e enmendar según albedrío de algunos omes buenos, que sean escogidos para esto de los Juezes ordinarios de aquel lugar, do tal cosa acaesciesse". (Partidas, III, 4, 23). Al respecto puede consultarse a BARONA (2005), p. 1330. Véase también a GASPAR (1998), pp. 38 y 39.

28 "E de si deven decir, en que manera otorgan poderio a los avenidores, que delibren estos pleytos, que ponen en su mano: porque ellos non han poderio de oyrlos, nin de librarlos, si non de aquellas cosas, e en aquella manera, que las partes gelo otorgaren". Partidas, III, 4, 23.

${ }^{29}$ En la Partida V, 10, 5, que trata del arbitraje sobre las cuentas entre socios, se dice: “...Otrosi dezimos, que si algunos fiziessen pleyto en su compañía, desta guisa; que de cada uno dellos óbviese tanta parte en la ganancia, o en la pérdida, quanta dixesse alguno otro que nombrasen; e aquel que señalasen para esto, fiziesse las partes guisadas, e derechas, deven estar por su alvedrío. Mas si las fiziere desaguisadas, como si mandasse tomar mayor parte al uno, que al otro, en la ganancia, o en las pérdidas, non mostrando alguna derecha razon que lo mandava, estonce no valdria el albedrío; ante dezimos, que debe ser enderecado por alvedrío, de omes buenos, que caten, si alguno de ellos merece mayor parte, por ser mas sabidor, o por llevar mayor trabajo segund diximos en la ley ante dexta. E si fallaren que es assi devengela dar, según entendieren que es guisado; e si non manden que lo partan igualmente". 
manifestaciones dispersas ${ }^{30}$, constituyen la semilla del arbitraje forzoso sobre asuntos mercantiles en el Derecho castellano y, desde allí, en el Derecho chileno actual. La Ley XXIV, por último, establecía un elenco de asuntos que no podían someterse al conocimiento de avenidores, mejorando así en precisión con respecto a los cuerpos de leyes ya mencionados y, concretamente, sobre las materias de arbitraje prohibido.

Finalmente, y no obstante el carácter judicialista que se imprime también a la institución arbitral en las Partidas, se retoma igualmente en ellas el sistema de penas del Derecho romano, para el caso de incumplimiento del pacto arbitral. En caso contrario -esto es, si no se estipulaba la pena-, las partes no tendrían obligación alguna de cumplir la sentencia; salvo que ésta no fuere impugnada en el plazo de diez días contados desde su dictación (reiterándose así el sistema de confirmación tácita implantado en Roma por Justiniano ${ }^{31}$ ), o cuando tal ratificación era explícita ${ }^{32}$.

Con todo, el Código de las Siete Partidas no llegó a ser adoptado efectivamente por los pueblos de España, considerándoselo incluso como un código subsidiario por las Cortes de Alcalá en $1348^{33}$. A la dictación de las Partidas, en fin, le siguió la promulgación de las Leyes de Estilo ${ }^{34}$, el Ordenamiento de Alcalá (de 1348), las Ordenanzas Reales de Castilla (de 1485), el Ordenamiento

30 Ejemplo de lo señalado lo constituye la Carta de Hermandad entre los consejos de Santander, Laredo, Castro Urdiales, Vitoria, Bermeo, Guetaria, San Sebastián y Fuenterrabia, acordada el 4 de mayo de 1296, "para dirimir querellas y hacer prosperar el comercio". El sistema consistió en implementar una suerte de institución judicial de carácter arbitral para resolver las controversias surgidas entre miembros de las comunidades referidas, los que debían ocurrir a una tercera villa de la hermandad para someterse allí al juicio de hombres buenos elegidos por las mismas partes involucradas. Se decía al respecto en la Carta de Hermandad: "...Si los de Fuente arrabia hobieren querellado los de San Sebastian, o los de San Sebastian de los de Fuente arrabia, que vengan a Guetaria aquellos que el pleyto hobieren, e que demanden dos omes buenos dende de la villa a so placer de las partes, e que les libren luego so pleyto sin detenimiento ninguno". Confróntese, MERCHÁN (1981), p. 143, nota 54.

31 "E sobre todo deven prometer de guardar, e de obedece el mandamiento, e los juyzios, que los avenidores fiziessen sobre aquel pleyto, so cierta pena que peche la parte, que non quisiere estar por ello, a la otra que obedecio el mandamiento de los avenidores. Ca si pena non fuesse puesta, non serian tenudas las partes de obedecer el mandamiento, nin el juyzio, que diessen entrellos. Fueras ende si callasen, e lo non contradixessen, desde el dia que fuesse dada la sentencia, fatsa diez dias. Ca entonce, moguer non y fuesse puesta pena, tenudas serian las partes de guardar el juyzio..." Partidas, III, 4, 23.

32 "E si por aventura non fuese puesta, a la sazon que fueren escogidos los avenidores; entonces dezimos, que quien non se pagare del juyzio dellos, que lo debe decir luego, e non sera despues tenudo de obedecerlo. Mas si lo toviesen las partes por bueno, diciendo, cuando avian judgado, que se pagavan del juyzio; o escribiendo por sus manos la carta de la sentencia, que la confirmavan ... tal sentencia como esta debe valer". Partidas, III, 4, 35.

33 LeYes de Toro, "Introducción", en Academia de la Historia (1848), p. 553.

${ }^{34}$ Se trató básicamente de una recopilación de las sentencias dictadas por los tribunales españoles, aplicando las Siete Partidas y el Fuero Real. 
Real (de 1490) y las Leyes de Toro (de 1505), ninguno de los cuales contiene normas sobre arbitraje. Sin embargo, y considerando el carácter subsidiario que se le dio a las Partidas, según se dijo recién, parece acertado entender que sus normas sobre arbitraje fueron precisamente las aplicadas durante la vigencia de estos cuerpos y recopilaciones normativas ${ }^{35}$.

\section{Nueva y Novísima Recopilación}

Tras el descubrimiento de América, en el siglo XVI, surgió en España la necesidad de trazar las pautas de un nuevo ordenamiento que pudiese ajustarse a las particulares relaciones con las Indias, conservando no obstante las bases del Derecho castellano. Sin embargo, y al mismo tiempo, desde fines del siglo $\mathrm{XV}$ las regulaciones castellanas se encontraban dispersas en una multiplicidad de fueros locales y en el Derecho oficial emanado de diversas leyes y ordenanzas dictadas por el rey y las Cortes ${ }^{36}$, lo que reforzaba la necesidad de volver a recopilarlo y refundirlo.

En 1567, durante el reinado de Felipe II, se promulga la Nueva Recopilación, que en sus nueve libros reúne las normas contenidas en ordenamientos anteriores (principalmente el Ordenamiento de Alcalá, el Fuero Juzgo, Fuero Real y las Leyes de Estilo). Sus normas, sin embargo, fuente de múltiples dudas y confusiones, debieron ser reestudiadas durante el reinado de Carlos IV, quien en el año 1805 dictó en su reemplazo la Novísima Recopilación.

Tanto la Nueva como la Novísima Recopilación, aunque parcas al referirse al arbitraje,mantienen la consideración del árbitro como juez y lo tratan conjuntamente con los jueces ordinarios ${ }^{37}$. Ambas recopilaciones conservan también la distinción entre jueces árbitros de Derecho -árbitros juris-y Jueces amigos o árbitros arbitradores, permitiendo el recurso a ellos de manera amplia e incluso respecto de asuntos ya fallados si las partes así lo acordaban ${ }^{38}$; pero al mismo

35 Esta idea se confirma en la Ley Primera de las Leyes de Toro, que señalan: "...Por las quales leyes de este nuestro libro mandamos que se libren primeramente todos los pleytos Civiles y Criminales, y los pleytos, y las contiendas que no se pudieren librar por las leyes de este nuestro libro, y por los dichos fueros, mandamos que se libren por las leyes de las siete partidas que el rey D. Alfonso nuestro bisabuelo mandó ordena, como que hasta aqui no se halla que fuesen publicadas por mandados del Rey, ni fueron avidas ni recibidas por leyes".

36 Tras el matrimonio de los Reyes Católicos y la unión de Castilla y Aragón, se produce un reforzamiento del Derecho emanado del Rey, con la consiguiente y paulatina decadencia de los Derechos locales.

37 "Ningun hombre sea osado de juzgar pleyto, sino fuere Alcalde puesto por Nos, ó á placer de las partes que lo tomen por avenencia para juzgar algun pleyto". Nueva Recopilación, IV, 21, 4; Novísima Recopilación, $\mathrm{XI}, 1,2$.

38 "Porque acaece, que las partes por bien de paz y concordia, y por evitar costas y pleytos y contiendas, ántes de entrar en contienda de juicio, y otras veces estando pleytos pendientes en el nuestro Consejo y en las nuestras Audiencias, ó ante otros Jueces, y algunas veces teniendo la parte sentencia 
tiempo incorporan, por primera vez en el ordenamiento jurídico español, la posibilidad de apelar de la sentencia de unos y otros (sin perjuicio de la nulidad del laudo y del recurso de reducción y albedrío de buen varón, que se mantiene), con la consiguiente intervención de la justicia ordinaria en el fondo del asunto sometido al conocimiento de árbitros y, por ende, con la consustancial desnaturalización de la institución arbitral en cuanto tal ${ }^{39}$.

Establecen, además, un régimen de ejecución inmediata de las sentencias arbitrales -lo que también constituye una novedad en relación a los cuerpos legales anteriores-, previo afianzamiento de la obligación de restituir lo recibido con sus frutos, para el caso en que la sentencia fuere después revocada ${ }^{40}$.

\section{El arbitraje a partir del siglo XIX}

El siglo XIX, con su potente corriente codificadora inspirada en la legislación napoleónica y en las ideas de libertad y autonomía de la persona humana surgidas de la Revolución francesa, se caracteriza por la marcada presencia que adquiere el arbitraje como alternativa de solución de conflictos y, en un extremo, con preeminencia incluso frente al sistema jurisdiccional estatal, según pasamos a revisar.

En España, la consagración expresa del arbitraje adquirió su más notoria expresión con la dictación de la Constitución de Cádiz de 1812, que lo consideró como un derecho fundamental y medio alternativo preponderante de resolución de controversias ${ }^{41}$.

Se reconoció además, por primera y única vez en el ordenamiento constitucional español (artículo 281), el carácter obligatorio y ejecutable de la decisión contenida en la sentencia arbitral; pero se mantuvo al mismo tiempo la posibilidad de apelar de la misma cuando las partes así lo habían estipulado en el compromiso, reiterándose así -aunque matizado por esta alusión al

ó sentencias en su favor pasadas en cosa juzgada, sabiéndolo, acuerdan de poner y comprometer los tales pleytos y contiendas en manos de Jueces árbitros juris, para que determinen conforme á Derecho, ó de Jueces amigos, árbitros arbitradores, y prometen de estar por la sentencia que dieren...". Nueva Recopilación, IV, 21,4; Novísima Recopilación, XI, 17, 4.

39 Nueva Recopilación, IV, 21,4; Novísima Recopilación, XI, 17, 4.

${ }^{40}$ Este carácter ejecutorio de la sentencia arbitral fue tomado de la Ley de Madrid, compuesta a su turno por las Ordenanzas de Madrid (1502) y algunas disposiciones de las Cortes de Toledo (1529).

${ }^{41}$ Su antecedente inmediato fue la Constitución francesa de 3 de septiembre de 1791, que consideraba al arbitraje como el mecanismo más razonable de resolución de conflictos y como un derecho fundamental de los ciudadanos, al señalar en su artículo 5': "le droit des citoyens de terminer définitivement leurs contestations pa la voie de l'arbitrage, ne peut recevoir aucune atiente par les actes du povoir legislatif". 
acuerdo previo- el retroceso que en este aspecto habían mostrado la Nueva y la Novísima Recopilación ${ }^{42}$.

En la Constitución de 1812, en síntesis, la facultad de las partes para someter sus asuntos disponibles a la resolución de árbitros fue expresamente reconocida entre sus normas fundamentales, en cuanto expresión de la libertad de la persona humana como principio filosófico-político rector de todas sus disposiciones ${ }^{43}$. Como contrapartida, la Carta Fundamental no hizo referencia alguna a la tutela judicial efectiva como derecho fundamental de los ciudadanos, procurando por esa vía limitar al máximo la intervención de los jueces estatales para potenciar desde allí el recurso a métodos alternativos de heterocomposición ${ }^{44}$. Como señala Mejías ${ }^{45}$, refiriéndose al tenor de los artículos 280 y 281 de la Constitución, "tales artículos vendrían a garantizar lo que podría denominarse 'derecho a la tutela arbitral', en paralelo a un inexistente reconocimiento del 'derecho a la tutela judicial'" .

A partir de la Carta de 1812, las sucesivas Constituciones españolas del siglo XIX $(1837,1845,1856$ y 1869) no vuelven a mencionar siquiera la institución del arbitraje, cuya regulación fue recogida en cambio en los Códigos procesales de la época.

\subsection{El arbitraje en la fase de codificación}

Durante la primera parte del siglo XIX el arbitraje adopta una nueva perspectiva y se incorpora especialmente en las nuevas codificaciones de la época, lo que da origen a una larga discusión doctrinal sobre la naturaleza contractual o jurisdiccional del mismo.

Por una parte, el arbitraje fue mencionado en el Código de Comercio de 1829 (artículos 323 y 345), en el Proyecto de Código Civil de 1851 (Libro III, Título XV) y en el Código Civil de 1889 (Libro IV, Título XIII, artículos 1820 y 1821), respectivamente, como manifestación clara del carácter jurídico-privado

\footnotetext{
${ }^{42}$ La disposición se refería al laudo arbitral como una "sentencia", que se ejecutaría de inmediato "si las partes al hacer el compromiso, no se hubieren reservado el derecho a apelar". Sin embargo, para entender esta disposición y el derecho de revisión que garantiza, se debe tener en cuenta el momento histórico al que me he referido y la concepción ideológica del Estado liberal que caracteriza a la Constitución de 1812, por lo que resultaba lógico -en ese contexto- reconocer también en ella la misma libertad de las partes para recurrir contra el laudo si así lo acordaban.

${ }_{43}$ En su exposición de motivos, la Constitución gaditana consideró esta facultad como "el derecho que tiene todo individuo de una sociedad a terminar sus diferencias por medio de jueces árbitros ... fundado en el incontrastable principio de libertad natural", lo que se plasma luego en el artículo 280 de su texto.

${ }^{44}$ La razón de ello es clara: se trataba de jueces que venían del antiguo régimen y a los que ahora, con el principio de separación de los poderes del Estado recién implantado, se les dotaba de independencia y autonomía.

45 Mej́́As (1998), p. 16.
} 
que se le otorgó al compromiso y, desde allí, como fundamento para quienes propugnaron la naturaleza contractualista de la institución en su conjunto; pero por otro lado, sin embargo, fueron los Códigos procesales los que lo regularon y desarrollaron efectivamente como un juicio más -aunque con características propias-, manteniendo por ende la corriente judicialista iniciada siglos antes en el Liber ludiciorum según paso a comprobar.

\section{A) Ley de Enjuiciamiento sobre los Negocios y Causas de Comercio}

En primer término, la Ley de Enjuiciamiento sobre los Negocios y Causas de Comercio, de 24 de julio de 1830, regulaba en su Título VI el arbitraje de derecho y de equidad, conceptualizándolos como juicio arbitral strictu sensu y de amigable componedor, respectivamente.

En lo que concierne a la posibilidad de revisión y control jurisdiccional del laudo arbitral, la ley de 1830 permitía por regla general el recurso de apelación en los casos de arbitraje de derecho, salvo contadas excepciones. En el arbitraje de equidad, en cambio, la apelación del laudo no estaba permitida.

La Ley procesal de 1830, por último, incorpora en su artículo 255 la figura del arbitraje forzoso cuando se trataba de dirimir controversias entre $\operatorname{socios}^{46}$, recogida antes por el Código de las Siete Partidas (Partida V, 10,5) y luego por las Ordenanzas de Bilbao de 1737. Este mismo fenómeno se presenta también en el derecho histórico francés, en donde la obligatoriedad del arbitraje aparece ya en un edicto del mes agosto de 1560, dictado durante el reinado de Francisco II de Francia, que hizo obligatorio el arbitraje en los negocios entre parientes y entre comerciantes por asuntos relativos a su comercio, lo que alcanzaba por ende a los socios de sociedades mercantiles ${ }^{47}$. Posteriormente, la Ordonnance de Commerse Terrestre de 1673, iniciativa esta vez del ministro Jean-Baptiste

\footnotetext{
${ }^{46}$ La norma, que se remitía a su vez a los artículos 323 y 345 del Código de Comercio de 1829, fue tomada al parecer de la Ordenanza de Bilbao de 1737, Capítulo X, Ley 16, que a su vez se habría inspirado en la legislación francesa y, concretamente, en un Edicto de 1560, bajo el reinado de Francisco II de Francia, que hacía obligatorio el arbitraje en los negocios entre parientes y entre comerciantes; y en la Ordonnance de Commerse Terrestre de 1673, iniciativa de Jean-Baptiste Colbert, Ministro de Luis XIV, que estableció la obligatoriedad del arbitraje respecto de los conflictos surgidos entre socios de compañías mercantiles, prescribiendo al efecto que todo estatuto social debía contener "la cláusula de someterse a los árbitros para las controversias que sobrevengan entre los asociados y, aun cuando la cláusula fuere omitida, uno de los asociados podrá nombrarlo, estando los demás obligados a actuar de igual manera pues, en caso contrario, será nombrado por el Juez para quienes se han rehusado a hacerlo". Confróntese, Roca (1992), p. 109.

${ }^{47}$ Este sistema concluyó, sin embargo, pocos años después, al organizarse en Francia la jurisdicción consular que comprendía todos los conflictos comerciales, partiendo con un Edicto de 1563 (que instituyó el Tribunal de Comercio de París) y continuando luego con otros tantos que extendieron la misma jurisdicción al resto de Francia, que incluía precisamente todas aquellas controversias o dife-
} 
Colbert durante el reinado de Luis XIV, estableció la obligatoriedad del arbitraje respecto de los conflictos surgidos entre socios de compañías mercantiles, prescribiendo al efecto que todo estatuto social debía contener "la cláusula de someterse a los árbitros para las controversias que sobrevengan entre los asociados y, aun cuando la cláusula fuere omitida, uno de los asociados podrá nombrarlo, estando los demás obligados a actuar de igual manera pues, en caso contrario, será nombrado por el Juez para quienes se han rehusado a hacerlo". 48 Poco más de un siglo después, la Ley de 16 y 24 de agosto de 1790 reiteró el carácter obligatorio del arbitraje en materia de conflictos societarios y, por último, el Código de Comercio francés de 1807 amplió la mencionada figura forzosa a las sociedades de capital, al señalar en su art. 51 que "toda controversia entre socios y por razón de la sociedad, será juzgada por árbitros". ${ }^{49}$

\section{B) Ley de Enjuiciamiento Civil de 1855}

En la Ley de Enjuiciamiento Civil -LEC- de 5 de octubre de 1855, el arbitraje es tratado también como un juicio y vuelve a ser clasificado en arbitraje de derecho (Título XV, "Del Juicio Arbitral") y de equidad (Título XVI, "Del juicio de amigables componedores"), lo que repercutía también en la posibilidad y forma de impugnar el laudo. Paralelamente, sin embargo, el Código Civil hablaba simplemente de compromiso, sin distinción alguna.

Respecto del arbitraje de derecho, la ley mantuvo el criterio de permitir en su artículo 814 el recurso de apelación contra el laudo, aunque ahora sin más restricciones que el pago de una multa que debía pagar el apelante al apelado

rencias ocurridas en el seno de "compañías, sociedades o asociaciones constituidas o por constituir". Confróntese, MuÑOZ (1978), p. 386.

${ }^{48}$ Artículo 9 del Título IV de la Ordenanza (traducción libre del autor).

Con posterioridad a la Revolución, además, la importancia del arbitraje en Francia fue exagerada al punto de hacerse obligatorio para los negocios entre parientes y, en la práctica, para todos los negocios en general, en contrapeso y como resguardo ante la autonomía e independencia con que se dotaba ahora a los jueces en cuanto miembros de uno de los poderes del Estado, que provenían, sin embargo, del antiguo régimen. Sentís señala al respecto que tras la Revolución francesa surgió una marcada tendencia por suprimir toda manifestación del régimen judicial antiguo, lo que se manifiesta claramente en una ley del mes de Brumario del año II de la República francesa (año 1794 del calendario gregoriano), que hizo "tabla rasa del procedimiento, pues pretendió regular todo el procedimiento en solos 17 artículos, pero la verdad es que suprimió los abogados, las costas judiciales y casi los jueces, pues los reducía a la categoría de árbitros públicos". Tan desproporcionada fue esta legislación que, al discutirse años después el Código de Procedimiento Civil de Napoleón de 1806, y como reacción a ella, el arbitraje estuvo a punto de ser eliminado como sistema de heterocomposición, aun cuando estuviere originado en la voluntad de las partes. Finalmente, sin embargo, "prevaleció con el carácter de institución voluntaria". SENTís (1934), p. 135.

${ }^{49}$ Traducción libre del autor. Con la Ley de 17 de julio de 1856 se eliminó definitivamente la figura del arbitraje obligatorio en el Derecho francés. 
que se conformaba con el fallo, para ser oído en la segunda instancia (artículo 774.7). La mayor novedad fue que el art. 816 amplió incluso la posibilidad de revisión jurisdiccional del laudo por vía de recurso extraordinario de casación, interpuesto ahora en contra del fallo de apelación de la entonces Audiencia del Distrito.

En cuanto al arbitraje de equidad, hasta entonces inatacable según se dijo más arriba, la ley para la reforma de la casación civil, de 1870, permitió también el recurso de casación para ante el Tribunal Supremo, sobre la base de causales específicas señaladas en la misma ley modificatoria. El mismo tratamiento impugnatorio fue luego recogido por la Ley de 1881.

Por último, la Ley de 1855 elimina toda referencia al arbitraje forzoso, retomando definitivamente la senda de voluntariedad que caracteriza la esencia de la institución y que se mantiene hasta hoy en el Derecho español, con algunas excepciones que han sido sin embargo superadas según se verá en el capítulo siguiente.

\section{C) Ley de Enjuiciamiento Civil de 1881}

En la Ley de Enjuiciamiento Civil de 1881, por su parte, que influyó también en la normativa contenida en el Código de Procedimiento Civil de 1902, la tendencia de regular el arbitraje como juicio -aunque no encuadrable en las demás figuras procesales- no presenta mayores modificaciones, unificándose simplemente en el Libro II, Título V, sobre jurisdicción contenciosa, los dos tipos de arbitraje que reconocía la LEC 1855 (artículos 790 al 839)

La sentencia arbitral -arbitraje de derecho- es generalmente apelable ${ }^{50}$, pero cobra carácter de ejecutoria tal como lo sería una sentencia judicial, con efecto de cosa juzgada, en los casos en que no se apelare. Contra la sentencia de la Audiencia del Distrito, por último, se reconoce también el recurso de casación, con lo que se equipara aún más a la sentencia arbitral con la que se dicta en un procedimiento judicial. En el arbitraje de amigables componedores, por su parte, se concede recurso de casación según se dijo más arriba.

\section{Conclusión preliminar}

En síntesis, al recorrer quince siglos de evolución jurídica en España hemos querido mostrar cómo los vaivenes y avatares de la historia, prolífica en culturas y tradiciones, han ido modelando la institución arbitral y marcado en ésta su huella a la par con las ideologías políticas y filosóficas que la han escoltado en el tiempo. Durante esos quince siglos, sin embargo, ha permanecido también

${ }^{50}$ Es la solución que se contempla hasta hoy en la legislación chilena, que en este aspecto muestra un significativo retraso. 
constante e inmutable un aspecto fundamental del arbitraje, propio de su esencia y que nutre su fisonomía en cuanto mecanismo alternativo de heterocomposición de conflictos, tal como lo hiciera en el Derecho Romano e incluso desde antes: me refiero a la autonomía de la voluntad y a la libertad individual, que se manifiesta a su turno en una doble dimensión: (a) una que puede calificarse como positiva, esto es, que las partes son libres para someter o no sus asuntos disponibles al conocimiento de árbitros, para que los resuelvan aplicando el derecho o criterios de equidad y con pleno efecto de cosa juzgada, sustrayéndolos de esta forma de la justicia ordinaria; y (b) otra negativa, esto es, que nadie pueda ser obligado como contrapartida a renunciar a esta última ${ }^{51}$.

\section{El arbitraje en la evolución legislativa chilena}

En el Derecho chileno la figura del arbitraje tiene sin duda una larga tradición jurídica, cuyos principales momentos y aspectos paso a revisar.

\section{Arbitraje en el derecho indiano}

En Chile, al igual que en el resto de los territorios conquistados de las Indias, se aplicaron en primer término las normas especialmente dictadas para América (Derecho Indiano propiamente tal) y, supletoriamente, el Derecho castellano vigente en el siglo XVI, al que ya me he referido.

En consecuencia, en materia de arbitraje la primera regulación aplicada en Chile provino del Código de las Siete Partidas, cuyas disposiciones sirvieron de base para la tramitación del primer arbitraje de que se tiene aquí noticia, seguido en el año 1544 entre Pedro de Valdivia y su socio Francisco Martínez de Vergara para resolver sobre la liquidación de la sociedad constituida entre ambos en Arequipa, en el año $1539^{52}$.

\section{Arbitraje en la época republicana}

Tras la emancipación en el siglo XIX siguió aplicándose en Chile la regulación contenida en las Partidas y, luego, en la Nueva y Novísima Recopilación, promoviéndose especialmente en un primer momento los mecanismos de la conciliación y del arbitraje como medios expeditos de hacer justicia ${ }^{53}$ (aunque sin llegar a hacerlo obligatorio en este último caso).

\footnotetext{
51 La única excepción se contiene en el Código de Comercio de 1829 y en su Ley procesal de 1830, que por algún tiempo introducen la figura del arbitraje forzoso en determinadas materias.

52 A este juicio arbitral se refiere DOUGNAC (2006), pp. 61 y 62.

53 Confróntese, Dougnac (1996), pp. 111 y ss.
} 
Una primera manifestación normativa que puede encontrarse sobre el arbitraje en el período de organización de la República en Chile se contiene en el proyecto de Constitución Política de Juan Egaña, de 1811, que se refería expresamente al arbitraje como medio alternativo de solución de disputas. El proyecto, si bien no llegó nunca a concretarse, procuraba privilegiar en efecto la vía del arbitraje para resolver de manera expedita los conflictos entre partes, recibiendo sin duda en esta parte el influjo de las corrientes ideológicas imperantes en la época de la ilustración y que sirvieron de base, en España, para la dictación de la Constitución gaditana de 1812.

En concreto, se creaba en este proyecto un Tribunal de paz (artículo 13), estableciéndose luego que en aquellos casos en que fallaba la avenencia ante sus jueces las partes podían optar entre someter la disputa respectiva al conocimiento de árbitros - si la materia lo permitía- o, en su defecto, ante la justicia ordinaria ${ }^{54}$. Para tal efecto, entre los meses de septiembre y octubre del mismo año el primer Congreso Nacional propuso incluso al Tribunal Supremo, de reciente creación, que despachara los reglamentos necesarios para la creación de los tribunales arbitrales encargados de resolver las contiendas referidas antes de recurrir a los tribunales ordinarios, lo que finalmente tampoco llegó a realizarse.

En el Reglamento Constitucional Provisorio de 26 de octubre de 1812 y, luego, en el Reglamento para el Gobierno provisorio de 1814, nada se dice sobre arbitraje, encomendándose en cambio la administración de justicia en forma exclusiva a los jueces ordinarios ${ }^{55}$.

Por su parte, en la denominada Constitución Provisoria de 1818, de 8 de agosto, se hacía una tímida referencia al arbitraje en su Título V, Capítulo III, artículo 25, señalándose allí: "Deberá establecerse un Juzgado de Paz, y en el ínterin lo será todo juez de primera instancia, que antes de darle curso, llamará a las partes y tratará de reducirlas a una transacción o compromiso extrajudicial; y poniéndose constancia de no haber tenido efecto esta diligencia, sólo correrá la demanda". Asimismo, y como apunta Dougnac ${ }^{56}$, el 24 de agosto de 1819 el Senado se vio en la necesidad de reforzar el cumplimiento y ejecución de los

\footnotetext{
${ }^{54}$ El texto completo del proyecto puede consultarse en Sesiones de los Cuerpos Legislativos de la República de Chile. 1811 a 1845 (1887), pp. 212 a 255.

55 El Reglamento de 1812 señalaba al respecto: “XVII. La facultad judiciaria residirá en los tribunales y jueces ordinarios. Velará el Gobierno sobre el cumplimiento de las leyes y de los deberes de los magistrados, sin perturbar sus funciones. Queda inhibido de todo lo contencioso". El de 1814, por su parte, establecía: "Los asuntos contenciosos en cualquiera de los ramos de Justicia, Hacienda y Guerra, se iniciarán o seguirán en la Intendencia de provincia. Los de provisiones de ejército y sus incidencias, en la de ejército".

${ }^{56}$ Dougnac (1996), p. 65. No es correcta sin embargo la referencia que este autor hace aquí a las Partidas, 3, 4, 35, por cuanto en ese cuerpo de leyes el laudo arbitral era inapelable, lo que cambia sólo a partir de la Nueva Recopilación, p. 41, nota 87, y p. 45, nota 100.
} 
fallos arbitrales, disponiendo al efecto que una vez comprometidas las partes y estipulada una multa en el mismo compromiso, "no se admite la apelación sin pagar previamente la pena señalada; y para el caso de que los comprometidos renunciaren al beneficio de la alzada, no pueda en tribunal alguno superior admitírseles la apelación o reclamación".

La Constitución Política de 1822, por su parte, hacía también una parca referencia al arbitraje en su Título VII, Capítulo III, "De los Jueces de Paz", creándose allí el denominado "Tribunal de Concordia". Según el artículo 191 de la Constitución, las funciones de dicho tribunal consistían en "conciliar y componer a los litigantes", agregando que en caso de no conseguirlo "procurarán se comprometan en hombres buenos..." ${ }^{\prime 57}$. Se mantiene entonces la concepción del arbitraje como una alternativa previa a la jurisdicción ordinaria, originada en todo caso de la voluntad de las partes.

La Constitución Política de 1823, de 29 de diciembre, conocida también como la Constitución moralista de Juan Egaña, contemplaba normas de arbitraje en su Título XVI, artículos 176 a 179, aunque bajo la nomenclatura de "Juicios prácticos"58, regulados a su turno en el Reglamento de Administración de Justicia de 1824, elaborado por Mariano Egaña y publicado como Ley el 2 de junio de ese año. Según el artículo 177 de la Constitución de 1823, en estos asuntos las partes podían ser compelidas en un plazo perentorio a designar ante el juez conciliador o el juez ordinario "a una o dos personas" que resolvieran sus disputas, las que podrían actuar como arbitradores si las partes así lo acordaban (en cuyo caso sus sentencias devenían en inapelables). Por otra parte, el artículo $149 \mathrm{~N}^{\circ} 8$ de la misma Carta Política facultaba a la Corte Suprema para obligar a compromiso ante uno de sus Ministros "en los negocios contenciosos que puedan ocasionar escandalosas disensiones y ruinas a las familias o al Estado", lo que se reglamentaba a su turno en el artículo 160 del Reglamento recién mencionado. En consecuencia, las normas referidas constituyen la primera manifestación de arbitrajes forzosos en el ordenamiento jurídico chileno, según veremos más adelante.

En la Constitución de 1828 se contempla nuevamente la figura de los jueces de paz, abandonándose en cambio los denominados "juicios prácticos".

Posteriormente la Constitución de 1833 no contempló normas sobre arbitraje ni se refirió al mismo en su articulado, limitándose a señalar en su artículo 114

\footnotetext{
57 Según Dougnac, esta norma habría sido tomada de la Constitución de Cádiz de 1812. Esa Carta Magna, sin embargo, no contemplaba en su articulado la institución de los jueces de paz, y si bien se refería a los "hombres buenos", les atribuía la función de conciliadores (artículo 283). Dougnac (1996), p. 65.

${ }^{58}$ Según el artículo 176, se trataba de conflictos en materia de "deslindes, direcciones, localidades, giros de aguas, internaciones, pertenencias de minas y demás objetos que esencialmente exigen conocimientos locales".
} 
que sería una ley especial la que regularía la organización y atribuciones de todos los Tribunales y juzgados de la República. En cumplimiento al referido mandato constitucional, con fecha 15 de octubre de 1875 se publicó la Lei de Organización y Atribuciones de los Tribunales de Chile, cuyo Título XI, artículos 172 a 191, estuvo íntegramente dedicado a los jueces árbitros ${ }^{59}$. Esta legislación, como señala Romero ${ }^{60}$, es la directa antecesora de la actual regulación que sobre la materia se contiene en el Código Orgánico de Tribunales, Título IX, artículos 222 a 243, introduciéndose definitivamente así la figura del arbitraje forzoso (interno) en la legislación procesal chilena, hasta nuestros días ${ }^{61}$.

Sin embargo, ya antes el Código Civil de 1855, vigente a partir del $1^{\circ}$ de enero de 1857, había contemplado normas sobre arbitraje en el Título X, Libro III, sobre partición de bienes, inspiradas sin duda en el Código de las Partidas aunque con carácter obligatorio. ${ }^{62}$ También el Código de Comercio de 23 de noviembre de 1865 , vigente desde del $1^{\circ}$ de enero de 1867 hasta hoy, se refirió al arbitraje entre las menciones que debían incluirse en el estatuto de una sociedad colectiva en punto a la forma en que debe verificarse la liquidación y

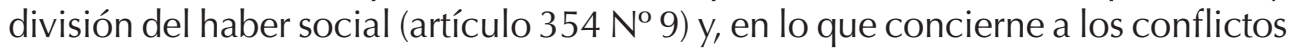
entre los socios, si éstos deben someterse o no a la resolución de arbitradores (artículo $\left.354 \mathrm{~N}^{0} 10\right)^{63}$.

Finalmente, el Código de Procedimiento Civil, promulgado el 28 de agosto de 1902, desarrolla el arbitraje interno en el Título IX, Libro III, “Del Juicio

59 Confróntese, VAlLe (1909).

${ }^{60}$ Romero (1999), p. 483.

${ }^{61}$ El artículo 176 de la Lei de organización... señalaba:

"Art. 176. Deben resolverse por árbitros los asuntos siguientes:

$1^{\circ}$ La liquidación de una sociedad conyugal o de una sociedad colectiva o en comandita civil;

$2^{\circ}$ La partición de bienes;

$3^{\circ}$ Las cuestiones a que diere lugar la presentación de la cuenta del jerente o del liquidador de las sociedades comerciales;

$4^{\circ}$ Las diferencias que ocurrieren entre los socios de una sociedad anónima, o de una sociedad colectiva o en comandita comercial, o entre los asociados en una participación, en el caso del art. 415 del Código de Comercio.

Pueden, sin embargo, los interesados resolver por sí mismos estos negocios, si todos ellos tienen la libre disposición de sus bienes i concurren al acto".

62 Tal obligatoriedad surge según se dijo de la Lei de Organización y Atribuciones de los Tribunales de Chile, de 1875, y luego del Código Orgánico de Tribunales de 1943, artículo 227 № 2. Según Somarriva, tal carácter se justificaría porque "la partición supone de ordinario actividad en el partidor, quien es el llamado a encauzar la partición cuando se producen roces y dificultades entre los interesados; lo que no se aviene con los jueces ordinarios civiles, cuya actuación es eminentemente pasiva". SOMARRIVA (1956), p. 91.

${ }^{63}$ Tal disposición sería complementada también por la Lei de organización y atribuciones de los Tribunales y posteriormente por el Código Orgánico de Tribunales, que siguiendo la tendencia del Código de Comercio español de 1829 y su ley procesal de 1830, hizo obligatorio el arbitraje sobre estas materias. 
Arbitral", artículos 628 a 644, complementando así las normas contenidas en el Código Orgánico de Tribunales con un marcado carácter jurisdiccional.

\section{Conclusiones}

1. El arbitraje, como mecanismo alternativo de resolución de conflictos, se funda desde sus más remotos orígenes históricos en la libertad y en la autonomía de la voluntad. La libertad en que se funda el arbitraje constituye además un derecho fundamental de la persona humana, reconocido expresamente en la Constitución Política de 1980.

2. El arbitraje forzoso se origina en España en la legislación medieval castellana del siglo XIII -Código de las Siete Partidas-, la que se aplicó en Chile hasta la dictación del Código de Comercio de 1865, la ley procesal de 1875 y finalmente el COT.

En Francia, por su parte, el arbitraje obligatorio se encuentra ya en normativas de los siglos XVI y XVII y especialmente en las ordenanzas del ministro Colbert, las que fueron recogidas posteriormente por el Código de Comercio napoleónico de 1807, que influyó también en el C. de Com. chileno de 1865.

Estas legislaciones tienen en común, a su vez, tres aspectos principales:

a) Todas ellas surgen en un contexto de absolutismo monárquico muy anterior al constitucionalismo moderno, en el que no se concebía siquiera la separación de funciones en el ejercicio del poder.

Lo dicho explica entonces la subsistencia ya endémica de figuras como el arbitraje forzoso, vigente hasta hoy en el ordenamiento positivo chileno sobre arbitraje interno pese a constituir una manifestación propia del derecho medieval. Surgido en efecto en una época en donde no se concebía siquiera la separación de funciones en el ejercicio del poder y en donde la justicia distributiva y conmutativa era impartida por y en nombre del rey, dada la ausencia de tribunales dedicados exclusivamente a ejercer la función jurisdiccional (como se conocen hoy en los sistemas constitucionales modernos), el origen del arbitraje forzoso se sitúa en un momento histórico que precede con mucho al constitucionalismo moderno y al iusnaturalismo racionalista, que surge de las ideas reformistas liberales de fines del siglo XVIII. En ese contexto, pues, puede entenderse acaso que en determinadas situaciones su fuente no haya sido ya la voluntad de las partes, sino excepcionalmente la voluntad del soberano impuesta por un acto de ley. Sin embargo, y mirada la misma figura a la luz de los derechos fundamentales de la libertad y de la tutela judicial efectiva que estructuran el moderno Estado de Derecho, la conclusión no puede ser la misma ${ }^{64}$.

\footnotetext{
${ }^{64}$ Sobre la inconstitucionalidad del arbitraje forzoso en Chile puede consultarse nuestro trabajo, JEQUieR (2011), pp. 453-498.
} 
b) Ellas influyeron directamente al legislador chileno, quien las tomó como base precisamente para la codificación mercantil y la legislación procesal ya mencionada.

c) La figura del arbitraje forzoso se aplicó fundamentalmente a asuntos comerciales y societarios, caracterizados por tratarse de conflictos entre comerciantes y entre parientes, en el caso de las sociedades personalistas, todos los cuales requerían de una solución rápida y especializada para restaurar o mantener la paz familiar. Los socios, en efecto, eran por lo general familiares entre sí -o estaban vinculados al menos por íntimas relaciones de confianza-, pues en aquel entonces sólo se conocían las "compañías", nacidas durante la baja edad media en el seno de las grandes familias italianas de comerciantes.

Se hace indispensable, por lo mismo, una pronta revisión de la normativa vigente en Chile sobre arbitraje interno, que suprima toda manifestación de arbitraje forzoso sobre asuntos societarios mercantiles y, en general, sobre materias disponibles en Derecho ${ }^{65}$.

3. El derecho histórico muestra que la intervención de los tribunales estatales en la revisión del mérito de los laudos arbitrales, a través de los recursos procesales de derecho común -apelación, casación-, es también una creación del derecho medieval castellano. En consecuencia, resulta indispensable proscribir también tal injerencia y restringir la intervención jurisdiccional a la revisión externa del laudo, a través de una acción de anulación por causales tasadas como la que consagra actualmente la Ley $N^{\circ}$ 19.971, sobre Arbitraje Comercial Internacional, y en general la Ley Modelo UNCITRAL de 1985.

Como se dijo supra, el mecanismo recursivo recién señalado, aplicable básicamente a los arbitrajes de derecho y mixto, se explica -más no se justifica- por sus antecedentes históricos y por la concepción que se tenía del arbitraje en el derecho medieval castellano, en donde el monarca se reservaba la facultad de impartir justicia y de intervenir en los procesos judiciales, aun cuando éstos se siguieran ante árbitros. La legislación chilena sobre arbitraje interno, por lo mismo, a diferencia de lo que ocurre en aquellos ordenamientos que cuentan con regulaciones modernas sobre arbitraje, admite todavía -y para estos casosla completa revisión del laudo arbitral por parte de los órganos jurisdiccionales estatales, aun en sus aspectos de fondo, resultando procedentes por ende los

${ }^{65}$ Cabe mencionar en este punto el Anteproyecto de "Ley de Arbitraje Interno", preparado por el Ministerio de Justicia el año 2013 y anunciado incluso en el Mensaje del Proyecto de Código Procesal Civil, como una de las leyes necesarias y complementarias del mismo. En dicho Anteproyecto se plantea un esquema renovado del arbitraje doméstico, tanto en sus aspectos funcionales como orgánicos, y se incluyen precisamente disposiciones que atañen a un arbitraje societario esencialmente voluntario, en cuya redacción participamos. Sobre este Anteproyecto y sus disposiciones en materia de arbitraje societario puede consultarse nuestro trabajo "Arbitraje societario y arbitraje forzoso en el Anteproyecto de Ley de arbitraje interno. Algunas propuestas", en PICAND (2014), pp. 195-239. 
recursos procesales en su contra en conformidad a las normas comunes (en particular los de apelación y casación formal y de fondo $)^{66}$.

Con todo, la circunstancia descrita desnaturaliza por completo la propia esencia de la institución arbitral, pues si las partes han optado libremente por este equivalente jurisdiccional es porque, precisamente, su intención ha sido sustraerla del conocimiento de los órganos estatales, que no deben intervenir por lo mismo en lo que concierne a la decisión de fondo del asunto controvertido.

Radicalmente distinta es la situación en la Ley sobre Arbitraje Comercial Internacional -LACI- No 19.971, que recoge en plenitud el principio de intervención restringida de los tribunales estatales en el juicio arbitral. Siguiendo el mecanismo de impugnación de la Ley Modelo UNCITRAL de 1985, en efecto, la LACI sólo contempla el denominado recurso de nulidad como "único recurso", del que conocerá la Corte de Apelaciones respectiva sobre la base de causales tasadas que apuntan al examen o revisión externa del laudo y no al mérito o contenido de la decisión de fondo (art. 34 de la LACI). Así lo señaló precisamente la Corte de Apelaciones de Santiago, al destacar que el recurso de nulidad está diseñado en la $\mathrm{LACl}$ como un recurso extraordinario y de derecho estricto, "donde la actuación del Tribunal se limita a verificar la concurrencia de las causales invocadas en relación a los hechos que las fundamentan. La acción otorga competencia a la Corte para examinar el cumplimiento de las formas del juicio arbitral, especialmente en cuanto a las garantías formales que la propia ley establece de modo imperativo, para asegurar una correcta génesis del laudo $^{\prime \prime 67}$. Entendemos también, por último, que contra la sentencia de la Corte de Apelaciones no procede el recurso de queja ante la Corte Suprema, pese a ejercer dicho tribunal la superintendencia directiva, correccional y económica de todos los tribunales de la Nación (art. 540 del COT). Así se desprende del carácter de lex specialis de la LACI, a lo que debe añadirse lo dispuesto por su art. $5^{\circ}$ cuando advierte que, en los asuntos regidos por ella, "no intervendrá ningún tribunal salvo en los casos en que esta ley así lo disponga".

\footnotetext{
${ }_{66}$ Un antecedente relevante en este sentido fue la Ley de Enjuiciamiento Civil española de 5 de octubre de 1855, que consideraba precisamente al arbitraje como un juicio y lo clasificaba en arbitraje de derecho (Título XV, "Del Juicio Arbitral") y de equidad (Título XVI, "Del juicio de amigables componedores"), lo que repercutía también en la posibilidad y forma de impugnar el laudo. Respecto del arbitraje de derecho, la ley permitía en su artículo 814 el recurso de apelación contra el laudo, sin más restricciones que el pago de una multa que debía pagar el apelante al apelado que se conformaba con el fallo, para ser oído en la segunda instancia (artículo 774.7). La mayor novedad fue que el art. 816 amplió incluso la posibilidad de revisión jurisdiccional del laudo por vía de recurso extraordinario de casación, interpuesto ahora en contra del fallo de apelación de la entonces Audiencia del Distrito.

67 Sentencia de 4 de agosto de 2009, C.5ㅜ, Rol No 9134-2007.
} 


\section{BibliografíA CitADA}

Academia de la Historia (1848): Los Códigos Españoles Concordados y anotados (Madrid, Imprenta de la Publicidad).

Alcala-Zámora y Castillo, Niceto (2000): Proceso, autocomposición y autodefensa (Ciudad de México, Edit. UNAM).

Alcover San Pedro, Amparo, Arbitraje Privado, Interno e Internacional, desde la Perspectiva Española, Tesis Doctoral (Facultad de Derecho, Departamento de Derecho Procesal, Universitat de València).

Barona Vilar, Silvia (2005): "Arbitraje y justicia en España en el siglo XXI", en Juris Poiesis (año 8, № 8, Río de Janeiro, julio).

Barona VILAR, Silvia (2005): "Fomento de los ADRs en España (Hacia un sistema de tutela plural del ciudadano que permita la desconflictivización y la búsqueda de la paz social)", en "Seqüência. Revista do Curso de Pós-Graduacão em Direito da UFCS" (№ 51, año XXV, diciembre de 2005).

BRISEÑO SieRRA, Humberto (1963): El arbitraje en el Derecho privado (Ciudad de México, Imprenta Universitaria).

Buigues Oliver, Gabriel (1990): La solución amistosa de los conflictos en Derecho romano: El arbiter ex compromisso (Madrid, Montecorvo).

Cervantes Bravo, Irina Graciela (2006): "El arbitraje como origen del proceso y su evolución histórica hasta la etapa de codificación del Derecho procesal español", en: Revista Vasca de Derecho Procesal y Arbitraje (Tomo XVIII, Universidad del País Vasco, Mayo), pp. 295-317.

Daza Martínez, Jesús y Rodríguez Ennes, Luis (1997): Instituciones de Derecho Privado Romano (Madrid, Closas-Orcoyen).

De RugGiero, Ettore (1971): L'arbitrato púbblico in relazione col privato presso i romani. Ristampa anastasica invariatta dell'edizione (Roma 1893, Roma).

Del Valle Valenzuela, Alfredo (1909): La Lei de organización y atribuciones de los Tribunales i sus modificaciones (Santiago, Cervantes).

Dízz-Picazo Giménez, Ignacio y Vegas Torres, Jaime (2004): Derecho Procesal Civil. Proceso concursal - Arbitraje (Madrid, Editorial Universitaria, Centro de Estudios Ramón Areces).

Dougnac Rodríguez, Antonio (2006): "Antecedentes históricos sobre la regulación del arbitraje en Chile", en PICAND AlbónICO, Eduardo (coord.), Estudios de Arbitraje. Libro Homenaje al profesor Patricio Aylwin Azócar, $1^{\text {a }}$ ed. (Santiago, Editorial Jurídica de Chile).

Dougnac Rodríguez, Antonio (1996): "La conciliación previa a la entrada en juicio en el derecho patrio chileno", en: Revista de Estudios Histórico-Jurídicos (No 18), pp. 111-168. 
FernÁNDEZ de Buján, Antonio (2006): Jurisdicción y Arbitraje en Derecho Romano (Madrid, lustel, Portal Derecho S.A.).

García Garrindo, Manuel Jesús (2000): Derecho Privado Romano: casos, acciones, instituciones (Madrid, Dykinson).

Gaspar Lera, Silvia (1998): El ámbito de aplicación del arbitraje (Pamplona, Aranzadi).

Jequier Lehuedé, Eduardo (2011): "El Arbitraje forzoso en Chile (Un examen de constitucionalidad en el ordenamiento jurídico chileno)", en: Revista de Estudios Constitucionales (Año 9, № 2), pp. 453-498.

Martínez García, Elena (2000): El arbitraje como solución de conflictos en propiedad intelectual, Tesis Doctoral (Facultad de Derecho Univesitat de València, Departamento de Derecho Procesal, Valencia).

MejíAs Gómez, Juan Francisco (1998): "Resolución alternativa de conflictos", en: Curso sobre Resolución alternativa de conflictos (Arbitraje, Conciliación), VV.AA. (Generalitat Valenciana, Consejo General del Poder Judicial).

MuÑoz Planas, José María (1978): "Algunos Problemas del arbitraje en materia de sociedades mercantiles", en VV.AA., Estudios de Derecho Mercantil en Homenaje a Rodrigo Uría (Madrid, Civitas).

Real Academia Española: Fuero Juzgo en latín y castellano. Cotejado con los más antiguos y preciosos Códices (Madrid, 1815).

Roca Martínez, José María (1992): Arbitraje e instituciones arbitrales (Barcelona, Bosch).

Romero Seguel, Alejandro (1999) "Nociones generales sobre la justicia arbitral", en Revista Chilena de Derecho (Vol. 26, № 2, 1999).

Sentis Melendo, Santiago (1934): Derecho Procesal Civil, Criminal y Organización Judicial (Apéndice a la 4a edición de la obra Organización de Tribunales y Leyes de Procedimiento) (Madrid, Reus).

Somarriva Undurraga, Manuel (1956): Indivisión y Partición (Santiago, Editorial Jurídica de Chile), Tomo II.

ValiÑo, Emilio (1976): Instituciones de Derecho Privado Romano (Universitat de Valencia, Facultad de Derecho).

VÁsquez Palma, Ma Fernanda (2009): Arbitraje en Chile(Santiago, LegalPublishing). 